\title{
Structure of the crust and the lithosphere in the Himalaya-Tibet region and implications on the rheology and eclogitization of the India plate
}

\author{
György Hetényi ${ }^{1+*}$, Jérôme Vergne ${ }^{1 x}$, John L. Nábělek ${ }^{2}$, Rodolphe Cattin ${ }^{1}$, Fabrice Brunet ${ }^{1}$, Laurent \\ Bollinger $^{3}$ and Michel Diament ${ }^{4}$
}

\author{
1 Laboratoire de Géologie, Ecole Normale Supérieure, CNRS - UMR 8538, 24 rue Lhomond, 5005 Paris, FRANCE \\ 2 College of Oceanic and Atmospheric Sciences, Oregon State University, Corvallis OR 97331, USA \\ 3 Laboratoire de Détection et de Géophysique, CEA, BP12, 91680 Bruyères-le-Châtel, FRANCE \\ ${ }^{4}$ Institut de Physique du Globe de Paris, 4 place Jussieu, 75252 Paris, FRANCE \\ + Present address: Institute of Geophysics and Tectonics, School of Earth and Environment, University of Leeds, Leeds, UK \\ ${ }^{x}$ Present address: Ecole et Observatoire des Sciences de la Terre, Strasbourg, FRANCE \\ * For correspondence, email: hetenyi@geologie.ens.fr
}

The Himalayas and the Tibetan Plateau are considered as the classical case of continental collision. The geophysical, geological and geochemical observations in this region as well as numerical modelling studies have been interpreted in the frame of different models of plateau formation, including continental subduction (Tapponnier et al. 2001, Haines et al. 2003), crustal thickening (England and Houseman 1986), and underplating (Argand 1924, Barazangi and Ni 1982, Owens and Zandt 1997). In the meantime, due to the uneven coverage and resolution of the data over the plateau, some fundamental questions concerning the evolution of the region's lithosphere are still pending. What are the main structural features of the collision zone? How do new constraints on structure influence our understanding of rheology? What are the physical processes which play a major role in the evolution of this system?

The "Himalayan-Tibetan Continental Lithosphere in Mountain Building" (Hi-CLIMB) project provides new data to bring answers to the questions on structure. This passive seismological experiment deployed a large number of broadband stations at 255 sites during three years. More than 150 closely spaced (4-9 km) stations form the main profile, spanning on 800 $\mathrm{km}$ along $85^{\circ} \mathrm{E}$, across the Himalayas and the southern half of the Tibetan Plateau. The remaining sites were deployed more sparsely and allow to map lateral structural variations. The large amount of data (1.5 terabyte), the high-frequency receiver functions and the use of multiply converted waves result in a detailed image of lithospheric structures at all scales. Two of the main results are as follows:

(1) We observe shallow and localized low-velocity layers in the Tibetan crust. These features, previously referred to as "bright spots", have a limited size both horizontally $(\sim 50 \mathrm{~km})$ and vertically $(\sim 10 \mathrm{~km})$. This, together with estimates of average crustal VP/VS-ratios between 1.7 and 1.8, does not support the presence of widespread partial melt. Moreover, the position of these low-velocity zones is strongly correlated to extensional grabens, which supports their localized occurrence, and suggests a rifting mechanism for their presence.

(2) Our images show underthrusting of the Indian lower crust beneath most of Lhasa block. The high resolution of the images allow to clearly follow the Moho of the India plate: its geometry descends smoothly beneath the Himalayas, reaching a maximum depth of $\sim 73 \mathrm{~km}$ b.s.l. at the Yarlung-Tsangpo suture, and then continues sub-horizontally for further $\sim 200 \mathrm{~km}$ to the North. The underthrusting is identified by the appearance of a second interface $\sim 15 \mathrm{~km}$ above the Moho, which is related to the top of the lower crust undergoing eclogite facies transformation (see below).

The conducted receiver function analyses also allow to:

(3) map faults at shallow $(\sim 3-4 \mathrm{~km})$ depth in Nepal;

(4) follow the Main Himalayan Thrust from its shallow part to its deep and ductile continuation;

(5) trace the main lithospheric boundary between India and Eurasia at about the centre of the plateau (south of and beneath the Banggong-Nujiang suture);

(6) conclude that the main sutures at the surface have no pronounced signature at depth;

(7) show that the upper mantle discontinuities at 410 and $670 \mathrm{~km}$ do not seem to be affected by the ongoing orogeny

The obtained information on the geometry of the structures are then used to bring answers to the questions on rheology and major physical processes.

The improved image on the flexural shape beneath the foreland basin allows to re-assess the rheology of the India plate using thermo-mechanical modelling. This reveals that flexural and thermal weakening causes decoupling of the lithospheric layers, which results in a south-to-north decrease of the effective elastic thickness. To explain the support of the Tibetan Plateau's topography as well as regional isostasy in the Himalayas, a strong upper mantle is required (Hetényi et al. 2006).

The geometry of underplating is combined with density models to reproduce observed Bouguer anomaly data. These models shows that localized densification of the Indian lower crust is occurs where it reaches its maximal depth. This effect is associated to eclogitization. Using thermo-kinematic and petrological models, we investigate the thermal field and pressuretemperature-density relations assuming different hydration levels, respectively. The results suggest partial hydration of the Indian lower crust, and kinetical hindrance of its eclogitization compared 
to phase equilibria. This overstepping is explained by the absence of free water in the system, and subsists until dehydration reactions occur at higher P-T conditions (Hetényi et al. 2007).

\section{References}

Argand E. 1924. La tectonique de l'Asie. In: Congrès Géologique Internationale, Bruxelles, Compte rendus de la XIIIe session 1: 171-372

Barazangi M and J Ni. 1982. Velocities and propagation characteristics of Pn and Sn beneath the Himalayan Arc and Tibetan plateau: possible evidence for underthrusting of Indian continental lithosphere beneath Tibet. Geology 10(4): 179-185

England P and G Houseman. 1986. Finite strain calculations of continental deformation. 2: Comparison with the India-Asia collision zone. Journal of Geophysical Research 91(B3): 3664-3676
Haines SS, SL Klemperer, L Brown, GR Jingru, J Mechie, R Meissner, A Ross and WJ Zhao. 2003. INDEPTH III seismic data: from surface observations to deep crustal processes in Tibet. Tectonics 22(1): 1001

Hetényi G, R Cattin, J Vergne and JL Nábělek. 2006. The effective elastic thickness of the India Plate from receiver function imaging, gravity anomalies and thermomechanical modelling. Geophysical Journal International 167(3): 1106-1118

Hetényi G, R Cattin, F Brunet, L Bollinger, J Vergne, JL Nábělek and M Diament. 2007. Density distribution of the India plate beneath the Tibetan Plateau: geophysical and petrological constraints on the kinetics of lower-crustal eclogitization. Earth and Planetary Science Letters 264(1-2): 226-244

Owens TJ and G Zandt. 1997. Implications of crustal property variations for models of Tibetan plateau evolution. Nature 387(6628): 37-43

Tapponnier P, ZQ Xu, F Roger, B Meyer, N Arnaud, G Wittlinger and JS Yang. 2001. Oblique stepwise rise and growth of the Tibet plateau. Science 294: 671-1677 